\title{
Efficacy of New Therapies for Relapse After Docetaxel Treatment of Bone Metastatic Castration-resistant Prostate Cancer in Clinical Practice
}

\author{
ATSUSHI MIZOKAMI ${ }^{1}$, KOSHIRO NISHIMOTO $^{2}$, HIDEYASU MATSUYAMA $^{3}$, TOMOHIKO ICHIKAWA ${ }^{4}$, \\ SATORU TAKAHASHI ${ }^{5}$, HIROAKI SHIINA ${ }^{6}$, KATSUYOSHI HASHINE ${ }^{7}$, YUTAKA SUGIYAMA ${ }^{8}$, \\ MANABU KAMIYAMA ${ }^{9}$, HIDEKI ENOKIDA ${ }^{10}$ and KENICHI NAKAJIMA ${ }^{11}$ \\ ${ }^{1}$ Kanazawa University Graduate School of Medical Science, Ishikawa, Japan; \\ ${ }^{2}$ International Medical Center, Saitama Medical University, Hidaka, Japan; \\ ${ }^{3}$ Department of Urology, Graduate School of Medicine, Yamaguchi University, Yamaguchi, Japan; \\ ${ }^{4}$ Department of Urology, Graduate School of Medicine, Chiba University, Chiba, Japan; \\ ${ }^{5}$ Department of Urology, Nihon University School of Medicine, Tokyo, Japan; \\ ${ }^{6}$ Department of Urology, Shimane University Faculty of Medicine, Matsue, Japan; \\ ${ }^{7}$ National Hospital Organization Shikoku Cancer Center, Matsuyama, Japan; \\ ${ }^{8}$ Department of Urology, Kumamoto University Faculty of Life Sciences, Kumamoto, Japan; \\ ${ }^{9}$ Department of Urology, Yamanashi University School of Medicine, Yamanashi, Japan; \\ ${ }^{10}$ Department of Urology, Kagoshima University Faculty of Medicine, Kagoshima, Japan; \\ ${ }^{11}$ Department of Nuclear Medicine, Kanazawa University Graduate School of Medical Science, Kanazawa, Japan
}

\begin{abstract}
Background/Aim: To assess the efficacy of novel therapeutic agents, such as androgen receptor axis-targeted agents (ARATs) and cabazitaxel, for relapse of metastatic castration-resistant prostate cancer $(m C R P C)$ after docetaxel in real-world practice, we performed a subanalysis using database from PROSTAT-BSI, a prospective observational study to evaluate the utility of software for quantifying bone metastases on bone scintigraphy. Patients and Methods: Patients with clinically relapsed $m C R P C$ after docetaxel treatment who received the new agents (NEW group) and those who did not (standard of care, SOC group) were included; patients who received ARAT before DOC treatment were excluded. Overall
\end{abstract}

Correspondence to: Atsushi Mizokami, MD, Ph.D., Department of Integrative Cancer Therapy and Urology, Kanazawa University Graduate School of Medical Science, 13-1 Takaramachi, Kanazawa, Ishikawa 920-8641, Japan. Tel: +81 762652393, Fax: +81 762344263,e-mail: mizokami@staff.kanazawa-u.ac.jp

Key Words: Bone metastatic castration-resistant prostate cancer, androgen receptor axis targeted agent, docetaxel, cabazitaxel, overall survival.

This article is an open access article distributed under the terms an conditions of the Creative Commons Attribution (CC BY-NC-ND) 4.0 international license (https://creativecommons.org/licenses/by-nc-nd/4.0).
Survival (OS) after docetaxel treatment was compared between the NEW and SOC groups. Results: Patients in the NEW group had significantly better OS from the start of docetaxel than those in the SOC group (the median OS in NEW and SOC was 28.9 months vs. 14.5 months, respectively). Furthermore, regardless of the time from androgen-deprivation therapy to the start of docetaxel at $m C R P C$, the NEW group had a better OS from relapse after docetaxel than the SOC group. Conclusion: In clinical practice, OS of patients with relapse after docetaxel was significantly improved in the NEW group over the SOC group.

Prostate cancer $(\mathrm{PCa})$ is the most common cancer in men in the United States and the second leading cause of death from cancer (1). Although androgen-deprivation therapy (ADT) is considered the standard therapy for metastatic hormone sensitive PCa (mHSPC), mHSPC progresses to metastatic castration-resistant prostate cancer (mCRPC) within a few years. Unfortunately, patients with CRPC after conventional hormonal therapy and docetaxel (DOC) usually have a life expectancy of less than 3 years $(2,3)$. Phase III clinical trials have confirmed that the novel androgen receptor axis-targeted agents (ARATs), such as abiraterone acetate and enzalutamide, improved overall survival (OS) of patients with mCRPC before and after DOC treatment, and therefore, they are now often used in clinical practice (4-7). Treatment with cabazitaxel (CBZ) for relapse after DOC treatment of patients with mCRPC also improved OS (8). A post-hoc analysis of the 


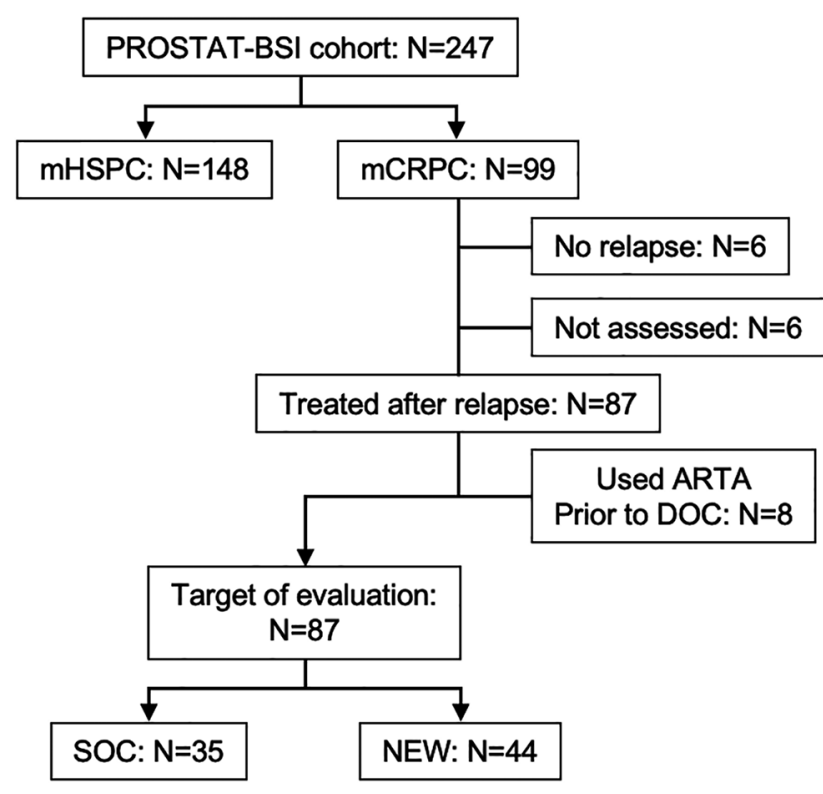

Figure 1. Diagrams of patients who relapsed after docetaxel treatment included in the current study. NEW group: the patients who were treated with new androgen receptor axis targeted agent (ARAT) and/or cabazitaxel (CBZ) after docetaxel treatment. SOC group: the patients who were not treated with new ARAT and CBZ after docetaxel treatment.

placebo-controlled PREVAIL trial in Japan revealed that enzalutamide for pre-DOC mCRPC improved OS similarly to global study $(9,10)$. Abiraterone acetate pre- or post-DOC treatment also showed favorable efficacy in Japanese patients with mCRPC $(11,12)$. In real-world clinical practice, however, there is still no sufficient evidence regarding the efficacy of novel ARATs and CBZ used in relapse after DOC treatment on OS because it is not ethical to conduct clinical trials comparing new ARATs with placebo in patients who have relapsed.

The PROSTAT-BSI multicenter prospective observational study was conducted in Japan from 2012 to 2018 to clarify the usefulness of bone scan index (BSI) based on BONENAVI software using neural networks (FUJIFILM Toyama Chemical, Tokyo, Japan) and bone scintigraphy, which was introduced for quantitative objective assessment of bone metastases in prostate cancer (13). In this study, patients with mHSPC and patients with mCRPC prior to DOC treatment were evaluated for various factors and treatments along with the BSI of bone metastases (14). Interestingly, this prospective observational study crossed the eras over the advent of novel ARATs and CBZ, allowing us to evaluate the real-world efficacy of novel ARATs and CBZ among Japanese with similar historical background. We, therefore, performed a sub-analysis of PROSTAT-BSI to evaluate the benefit of ARAT and CBZ after DOC treatment and the effect of the time from the start of ADT to the start of DOC on the benefit in patients with mCRPC.
Table I. Treatments after relapse.

\begin{tabular}{lcc}
\hline & SOC & NEW \\
& N=35 & N=44 \\
\hline Enzalutamide & $0(0)$ & $33(75.0)$ \\
Abiraterone acetate+prednisone & $0(0)$ & $20(45.5)$ \\
Cabazitaxel & $0(0)$ & $14(31.8)^{*}$ \\
Estrogen-related drugs & $2(5.6)$ & $4(9.1)$ \\
Dexamethasone & $0(0)$ & $2(4.5)$ \\
Ra-223 & $0(0)$ & $1(2.3)$ \\
Sr-89 & $1(2.9)$ & $1(2.3)$ \\
Platinum-based chemotherapy & $0(0)$ & $2(4.5)$ \\
Peptide vaccination & $1(2.9)$ & $2(4.5)$ \\
\hline
\end{tabular}

*All patients who used cabazitaxel have already used androgen receptor axis target agents. SOC: Standard of care.

\section{Patients and Methods}

Patients. Of the 99 patients with mCRPC and bone metastases enrolled in PROSTAT-BSI from 2012 to 2017, 79 patients who had clinical relapse after DOC treatment (PSA progression, BSI progression on bone scintigraphy) and who did not use new ARATs prior to DOC treatment were included in the study (Figure 1). This multicenter study is registered in the University Medical Information Network in Japan as UMIN00000-7858. The study protocols were approved by the Ethics Committee of the core center, Kanazawa University, and all the participating hospitals. Informed consent was obtained when all patients were enrolled in the PROSTAT-BSI study.

Treatments and follow-up examination. In Japan, the new ARATs (enzalutamide and abiraterone acetate) and CBZ have been covered by health insurance since 2014 and are now available for patients with mCRPC. The dose of DOC and treatment decision after relapsing DOC was determined by the attending physician. Patients with mCRPC prior to DOC treatment were enrolled, and clinicopathology and stage at diagnosis, date of ADT initiation, date of DOC initiation, and various biochemical data and degree of bone metastasis (BSI and hot spot number) by BONENAVI at the time of DOC initiation, were recorded. Since time to CRPC from primary ADT was not recorded in our protocol, time to DOC treatment from primary ADT was applied for surrogate of time to CRPC. Biochemical examinations and bone scintigraphy were performed every 3 months during the first year of DOC treatment and at least annually thereafter to collect data. These examinations were performed occasionally, such as at relapse. Relapse after docetaxel treatment was determined by the judgment of the physician (PSA relapse or radiographic progression). The observation period was up to 3 years after the start of DOC.

Statistical analysis. Values are expressed as mean \pm standard deviation. The OS was assessed by the Kaplan-Meier method and significance was assayed by the log-rank test. Comparison of various laboratory data between the two groups with and without new ARAT was performed by Mann-Whitney test. Comparison of Gleason score, visceral metastasis, and $\mathrm{T}$ stage between the two groups with and without new ARAT was performed by chi-square test. The 
Table II. Characteristics of patients in the SOC group and the NEW group.

\begin{tabular}{|c|c|c|c|c|c|c|c|}
\hline \multirow[b]{2}{*}{ Subgroup } & \multirow[b]{2}{*}{$\mathrm{N}$} & \multicolumn{3}{|c|}{$\mathrm{SOC}, \mathrm{N}=35$} & \multicolumn{3}{|c|}{ NEW, N=44 } \\
\hline & & Median & Range & $\mathrm{N}$ & Median & Range & $p$-Value \\
\hline Age (years) & 35 & 69 & $48-89$ & 44 & 70 & $52-81$ & 0.9003 \\
\hline $\mathrm{Hb}(\mathrm{g} / \mathrm{dl})$ & 35 & 11.7 & $8.1-15.0$ & 44 & 12.4 & $6.8-16.1$ & 0.0334 \\
\hline CRP (mg/dl) & 28 & 0.23 & $0.003-11.62$ & 36 & 0.225 & $0.02-10.15$ & 0.659 \\
\hline PSA (ng/ml) & 35 & 16.54 & $0.008-812.7$ & 44 & 21.8 & $0.15-539.9$ & 0.5201 \\
\hline Alp (IU/1) & 35 & 300 & $145-3012$ & 44 & 280 & $123-3450$ & 0.6964 \\
\hline I-CTP (ng/ml) & 31 & 6.6 & $2.7-54.1$ & 38 & 5.5 & $2.1-52.0$ & 0.1004 \\
\hline BSI $(\%)$ & 35 & 3.446 & $0.13-12.60$ & 44 & 1.65 & $0.03-8.89$ & 0.2205 \\
\hline Bone met HSN & 35 & 24 & $2-128$ & 44 & 16 & $1-110$ & 0.2205 \\
\hline Time from pADT to DOC (M) & 35 & 21.2 & $4.40-131.6$ & 44 & 18.05 & $5.60-127.6$ & 0.4933 \\
\hline Gleason score & & & & & & & 0.7223 \\
\hline Unknown & 1 & & & 1 & & & \\
\hline$\leq 7$ & 5 & & & 9 & & & \\
\hline 8 & 10 & & & 8 & & & \\
\hline 9 & 17 & & & 21 & & & \\
\hline 10 & 2 & & & 5 & & & \\
\hline Visceral metastasis & & & & & & & 0.3434 \\
\hline None & 28 & & & 34 & & & \\
\hline Unknown & 2 & & & 0 & & & \\
\hline Lung & 4 & & & 8 & & & \\
\hline Liver & 1 & & & 2 & & & \\
\hline T stage & & & & & & & 0.2891 \\
\hline$\leq \mathrm{T} 2 \mathrm{c}$ & 4 & & & 7 & & & \\
\hline $\mathrm{T} 3 \mathrm{a}$ & 8 & & & 9 & & & \\
\hline $\mathrm{T} 3 \mathrm{~b}$ & 8 & & & 17 & & & \\
\hline $\mathrm{T} 4$ & 15 & & & 11 & & & \\
\hline
\end{tabular}

Hb: Hemoglobin; CRP: C-reactive protein; PSA: prostate specific antigen; Alp: alkaline phosphatase; 1-CTP: cross-linked telopeptide of type 1; BSI: bone scan index; Bone met HSN: Bone metastasis hot spot number; pADT: primary androgen deprivation therapy; DOC: docetaxel; SOC: standard of care.

univariable and multivariable proportional hazard analyses were used for patient groups with and without ARAT. All data analyses were performed by Prism 8 for MAC OS (GraphPad, San Diego, CA USA) or JMP version 14.3 (SAS Institute, Cary, NC, USA) and a $p$ value of $<0.05$ was considered statistically significant.

\section{Results}

Effect of new ARAT and CBZ after DOC treatment. Patients who received new ARAT prior to DOC treatment were excluded from this study because sequential therapy between new ARATs caused cross-resistance and the second ARAT was less effective $(15,16)$. These patients were then divided into two groups: those who were treated with new ARAT and/or CBZ after DOC (new agents, NEW group, 43 patients) and those who were not (standard of care, SOC group, 36 patients), and the efficacy of new agents on OS after relapse following DOC treatment was evaluated (Table I). All patients treated with CBZ had been previously treated with new ARAT in this study. Characteristics of these patient are shown in Table II. Baseline demographic and disease characteristics were well balanced between the two groups except hemoglobin prior to DOC treatment. Notably, there was no significant difference in the time from the primary ADT to the start of DOC treatment (a surrogate of time to CRPC) between NEW group and SOC group. The treatments for relapse after DOC treatment were shown in Table II. The median clinical progression free survival (PFS) after DOC treatment in mCRPC was 5.9 months (Figure 2A). The median clinical PFS after DOC treatment was better in the NEW group with a significant difference of 3.6 months and 6.8 months in the SOC and NEW groups, respectively ( $p=0.047$ ) (Figure $2 \mathrm{~B}$ ). The median OS from the start of DOC treatment and from the relapse after DOC treatment during the observation period was 26.5 months and 16.5 months, respectively (Figure 2C and D). As shown in Figure 3, patients treated with DOC followed by new therapeutic agents (NEW group) had significantly better OS from the start of DOC treatment than those who were not treated (SOC group) [the median OS: $28.9 v s .14 .5$ months, respectively, hazard ratio $(\mathrm{HR})=0.2705 ; 95 \%$ confidence interval $(\mathrm{CI})=0.1340-0.5463, p=0.0025]$ (Figure 3A). OS from the relapse after DOC treatment was also significantly better 
A Clinical PFS after DOC treatment

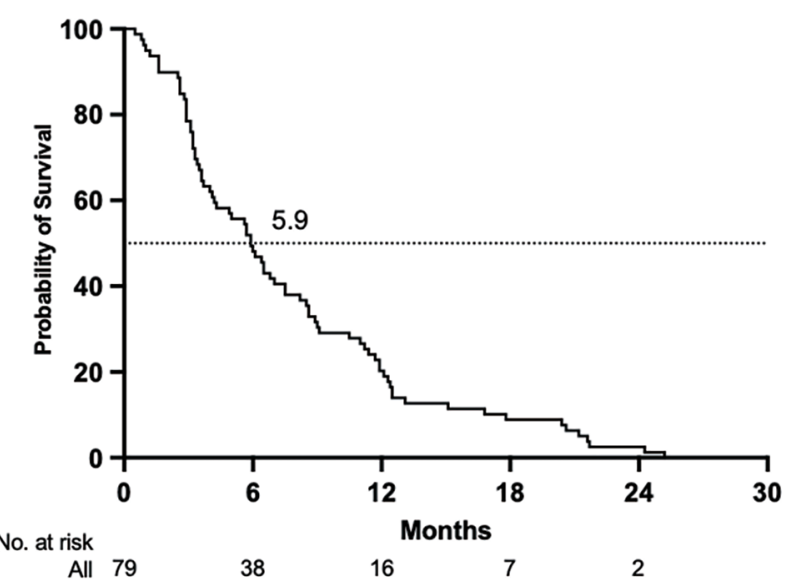

C

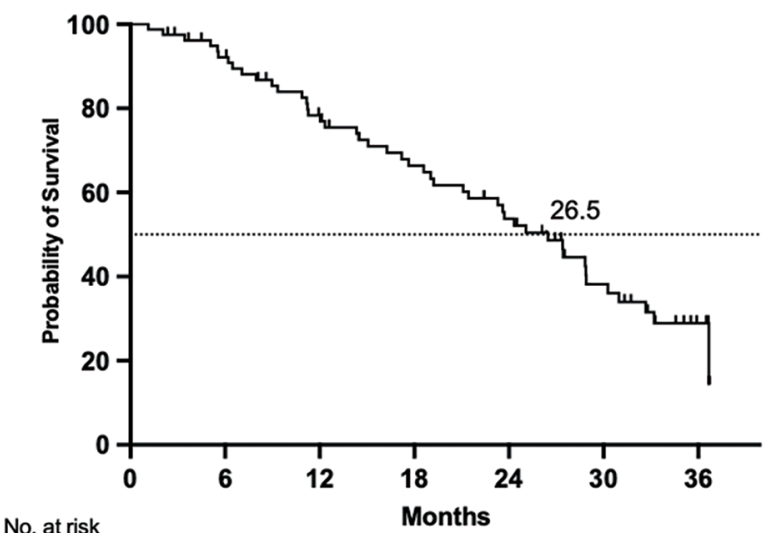

B Clinical PFS after DOC treatment in SOC and NEW

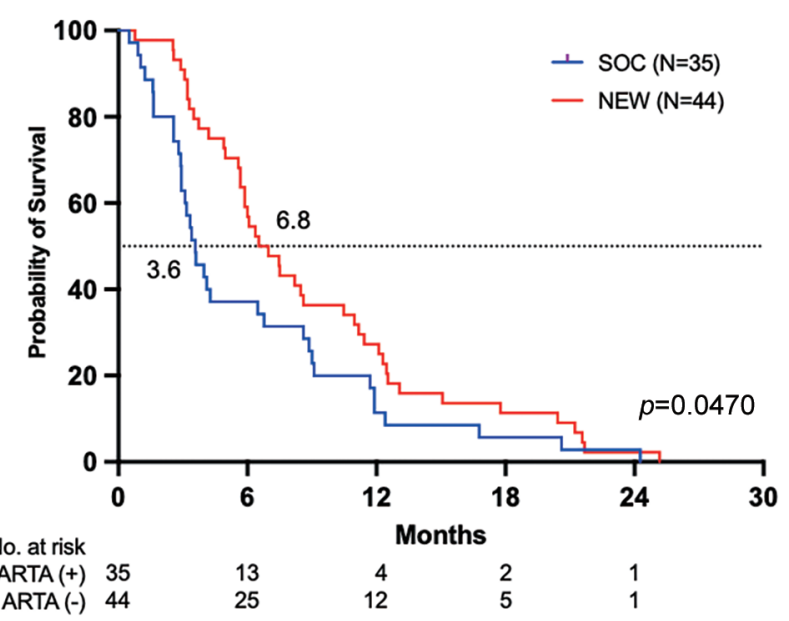

D

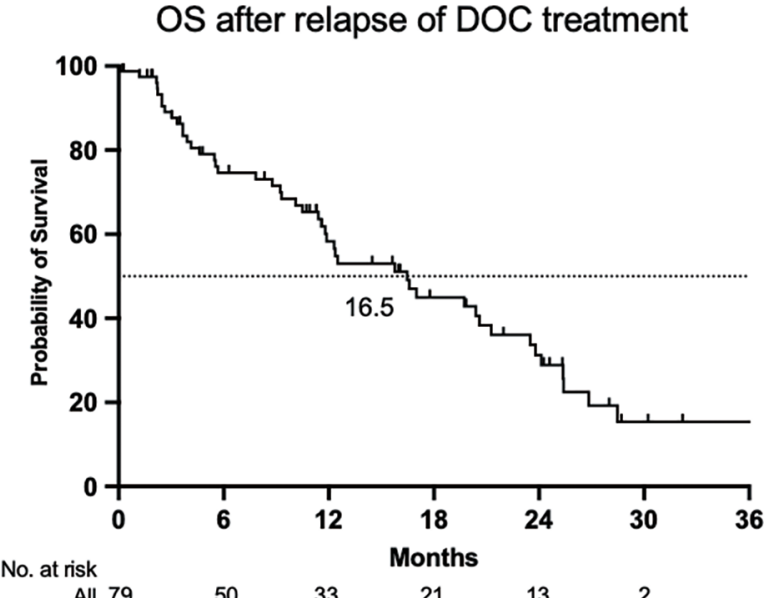

Figure 2. Clinical progression-free survival and overall survival after docetaxel treatment. A. Clinical progression-free survival after docetaxel treatment in all patients. B. Clinical progression-free survival after docetaxel treatment in the standard of care (SOC) group and the NEW group. C. Overall survival from the start of docetaxel treatment. D. Overall survival from the relapse of docetaxel treatment.

in the NEW group than in the SOC group (median: $20.6 \mathrm{vs}$. 8.9 months, $\mathrm{HR}=0.2705 ; 95 \% \mathrm{CI}=0.1340-0.5463, p=0.0003$ ) (Figure 3B).

Time to DOC treatment and $O S$. Some investigators reported that the longer the time to CRPC (TTCR) from the primary ADT, the better the OS, but the OS after CRPC did not change much regardless of whether the TTCR was long or short $(17,18)$. To confirm this, patients who relapsed after DOC treatment were classified into two groups according to the median time from primary ADT to the start of DOC treatment (median TTDOC: 20.2 months), instead of TTCR, and investigated the prognosis of these groups. The median OS of the groups of TTDOC $<20.2$ months and TTDOC $\geq 20.2$ months were 37.8 months and 83.8 months, respectively, and OS was significantly prolonged according to TTDOC $(p<0.0001)$ (Figure 4A). In contrast, the OS after relapse of DOC treatment in the groups of TTDOC $<20.2$ months and TTDOC $\geq 20.2$ months was 12.5 months and 20.6 months, which was not significant although longer TTDOC tended to have a better prognosis after relapse after DOC treatment (Figure 4B).

Since new therapeutic agents significantly prolonged OS after relapse following DOC treatment, we investigated the association between TTDOC and the efficacy of new therapeutic agents. In the group with TTDOC $<20.2$ months, patients in the NEW group had a significantly longer OS than patients in the SOC group after relapse following DOC 


\section{A OS after DOC between SOC and NEW}

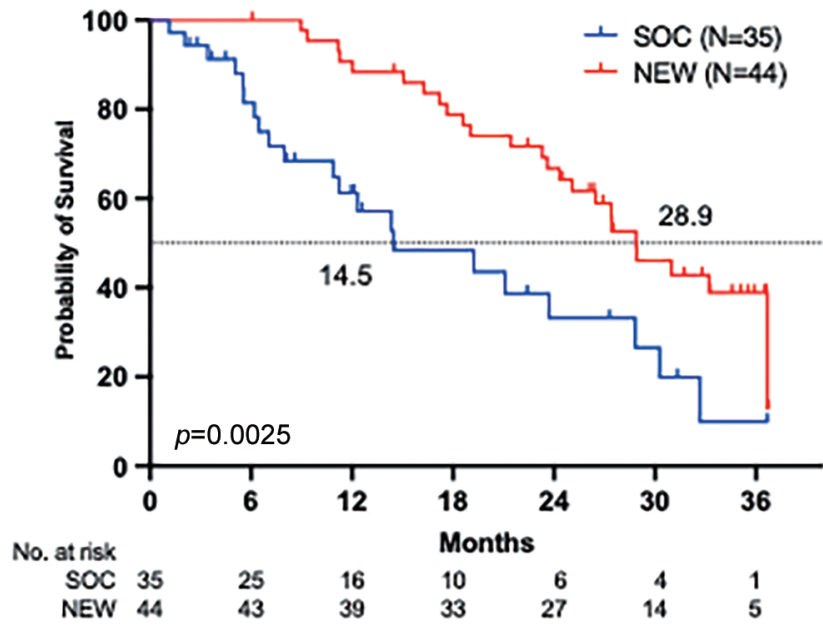

B OS after relapse between SOC and NEW

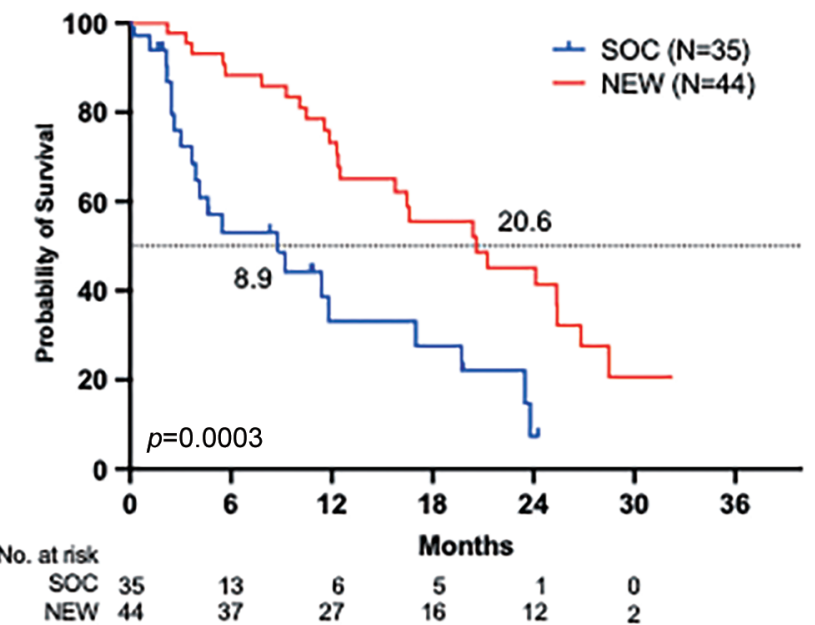

Figure 3. Comparison of overall survival between the standard of care (SOC) group and the NEW group A. Overall survival from the start of docetaxel treatment in the SOC group and the NEW group. B. Overall survival from the relapse of docetaxel treatment in the SOC group and the NEW group.

treatment (median OS: 16.5 months vs. 5.5 months, respectively. $\mathrm{HR}=0.2640 ; 95 \% \mathrm{CI}=0.1039-0.6705, p=0.0051$ ) (Figure 4C). In the group of patients with TTDOC $\geq 20.2$ months, OS after relapse of DOC treatment was also significantly longer in the NEW group than in the SOC group (median OS: 25.4 months vs. 11.8 months, respectively. $\mathrm{HR}=0.3350 ; 95 \% \mathrm{CI}=0.1171-0.9583, p=0.0414)$ (Figure 4D).

Effect of novel ARAT without CBZ after DOC treatment. Fourteen of the patients who received ARAT for relapse after DOC treatment also received CBZ. In order to evaluate the effect of ARAT alone on OS, patients treated with CBZ were excluded from the analysis. The median clinical-PFS after DOC treatment in mCRPC was 5.6 months (Data not shown). There was no significant difference in clinical PFS after DOC treatment between the SOC group and the NEW group (3.6 months and 6.0 months, respectively, $p=0.1736$ ) (Figure 5A). In contrast, the median OS after clinical PFS was 20.4 months in the NEW group, compared with 8.8 months in the SOC group, and OS was 11.6 months longer in the NEW group than in the SOC group $(p=0.0025)$ (Figure $5 \mathrm{~A}$ and $\mathrm{B})$. We also investigated the association between TTDOC and the efficacy of novel ARATs. In the group with TTDOC < 20.2 months, patients in the NEW group had a significantly longer OS than patients in the SOC group after relapse of DOC treatment (median OS: 16.5 months vs. 5.5 months, respectively; HR=0.3584; 95\%CI=0.1426-0.9010, $p=0.0051$ ) (Figure 5C). In the group of patients with TTDOC $\geq 20.2$ months, there was a trend of longer OS after relapse of DOC treatment in the NEW group than in the SOC group with a borderline significance (median OS: 21.3 months $v s$. 11.8 months, respectively; $\mathrm{HR}=0.3350 ; 95 \% \mathrm{CI}=0.1103$ $1.008, p=0.0517$ ) (Figure 5D).

Proportional hazard analysis for predicting death. All-cause death among patients in the mCRPC group was assessed by univariate proportional hazards analysis (Table III). The variables of hemoglobin, alkaline phosphatase (ALP), crosslinked telopeptide of type 1 (1-CTP), bone alkaline phosphatase (BAP), C-reactive protein (CRP), and bone scan index (BSI) and number of hot spots in bone-scintigraphy were significant predictors of all-cause death. In addition, time durations to PSA progression, BSI progression, and clinical progression were also associated with all-cause death. When the data were binarized with medians, 1-CTP $>6.0 \mathrm{ng} / \mathrm{ml}$ and CRP $>0.23 \mathrm{mg} / \mathrm{dl}$ showed worse hazard risk. In contrast, multivariate proportional hazards analysis using hemoglobin, ALP, 1-CTP, BAP, CRP, BSI, and the number of hot spots indicated that none of these variables were significantly different.

Groups with and without ARAT $(n=44$ and 35, respectively) were compared using proportional hazard analysis for the durations of time from the start of docetaxel and the clinical progression after docetaxel (Table IV). Univariable analysis (A) revealed that the use of ARAT significantly reduced mortality with hazard ratio of 0.415 ( $p=0.004)$ and $0.334(p=0.001)$ for the time from docetaxel and the time from clinical progression, respectively. However, CBZ did not significantly contribute to reduced mortality in this study. When patients with concomitant use of CBZ were excluded (30 with ARAT and 35 without 
A OS after primary ADT by TTDOC

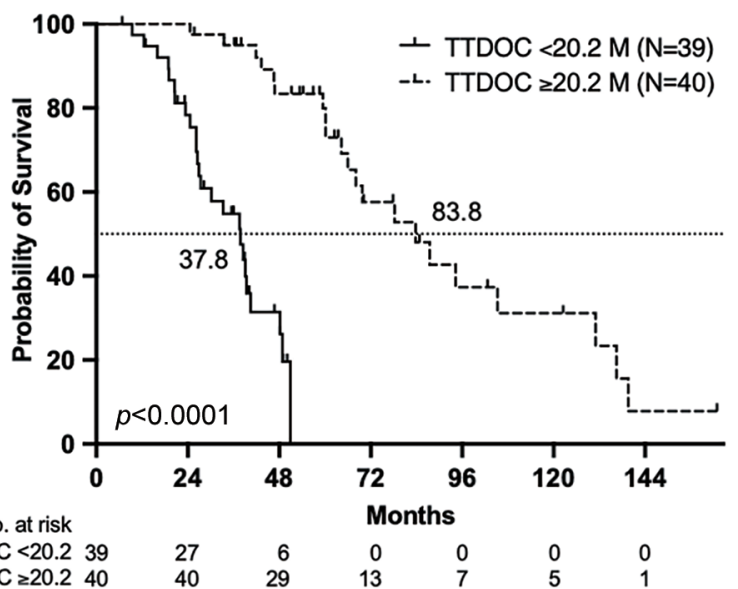

C

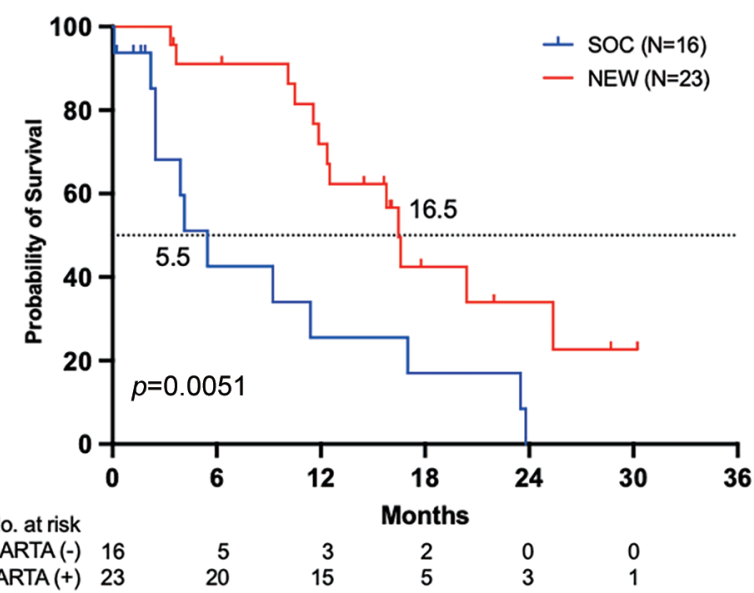

B OS after the relapse of DOC

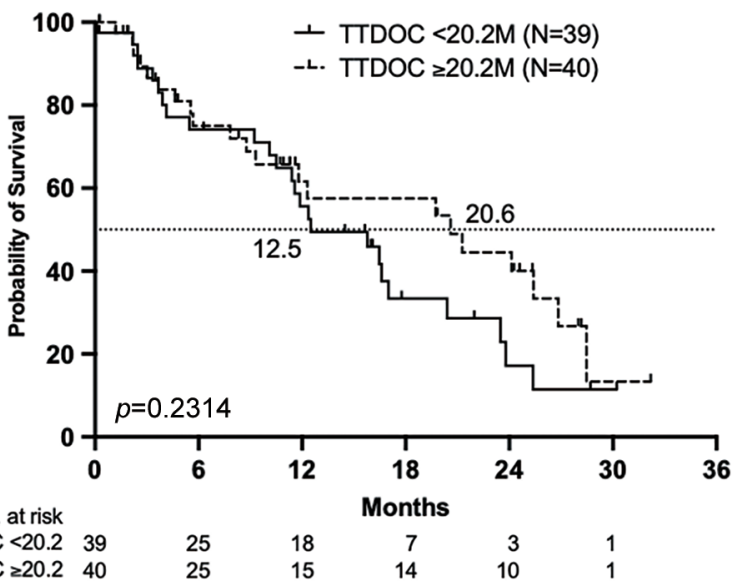

D TTDOC $\geqq 20.2 \mathrm{M}$

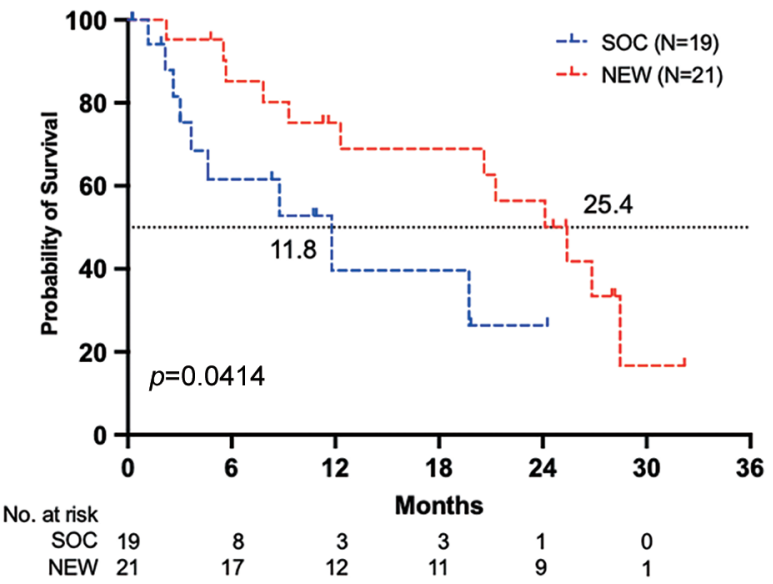

Figure 4. Length of time from primary androgen-deprivation therapy (ADT) to the start of docetaxel treatment (TTDOC) and overall survival. A. Difference in overall survival from the primary ADT by TTDOC. B. Difference in overall survival from the relapse following docetaxel treatment by TTDOC. C. Difference in overall survival from the relapse following docetaxel treatment in the standard of care (SOC) group and the NEW group (TTDOC $<20.2$ months). D. Difference in overall survival from the relapse following docetaxel treatment in the SOC group and the NEW group (TTDO $\geq 20.2$ months).

ARAT), significance of ARAT was similarly shown (B). Multivariable analysis (C) revealed that even when the use of ARAT was adjusted for PSA values, the use of ARAT was still significant for durations from docetaxel and clinical progression ( $p=0.015$ and 0.002 , respectively).

\section{Discussion}

At present, the only way to prove usefulness of novel therapeutic agents for mCRPC in actual clinical practice is to compare the OS of patients in the era when novel therapies were not available in routine practice with those in the era when they were available. in daily practice. Halwani et al. retrospectively compared the treatment of veterans with mCRPC in the era when novel ARATs were rarely used (20062010) and the era when novel ARATs were available (20112016), and showed that the median OS was extended for 8 months by new ARAT in mCRPC (3). Francini et al. also compared patients diagnosed with mCRPC between 20042007, an era with limited treatments, to patients between 20102013, treated also with newer therapies, and demonstrated that patients in the newer therapy era had an OS advantage ( $2.8 \mathrm{vs}$. 2.2 years) with a $41 \%$ decreased risk of death (19). Iwamura et al. also reported that in Japan, during the 2015-2018 era 
A Clinical-PFS after DOC w/o CBZ

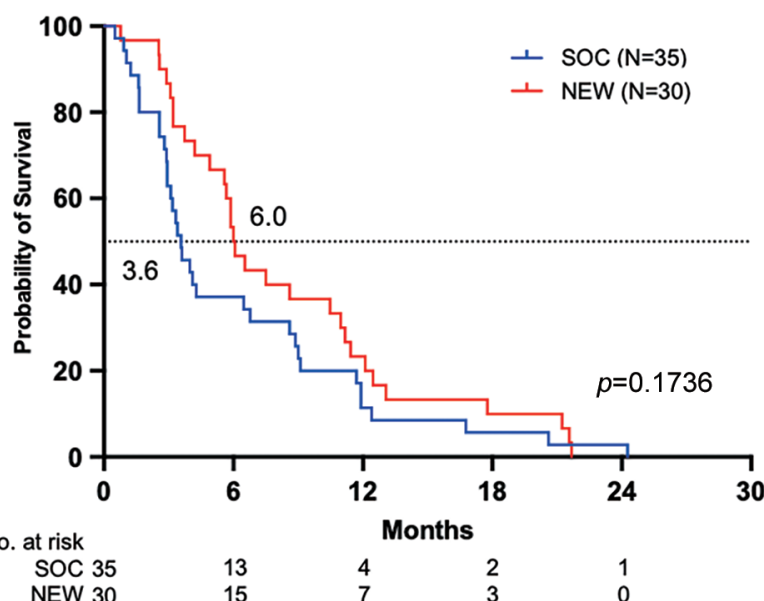

C TTDOC $<20.2 \mathrm{M}$

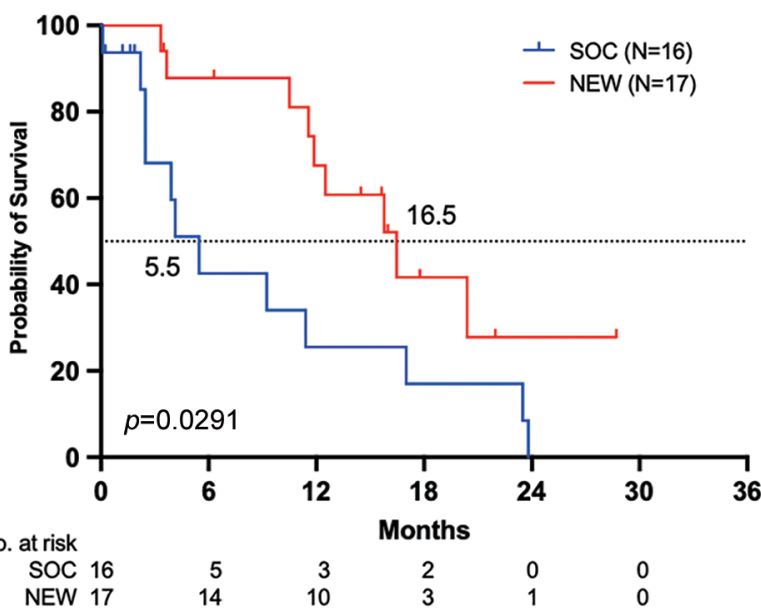

B OS after Clinical progression w/0 CBZ

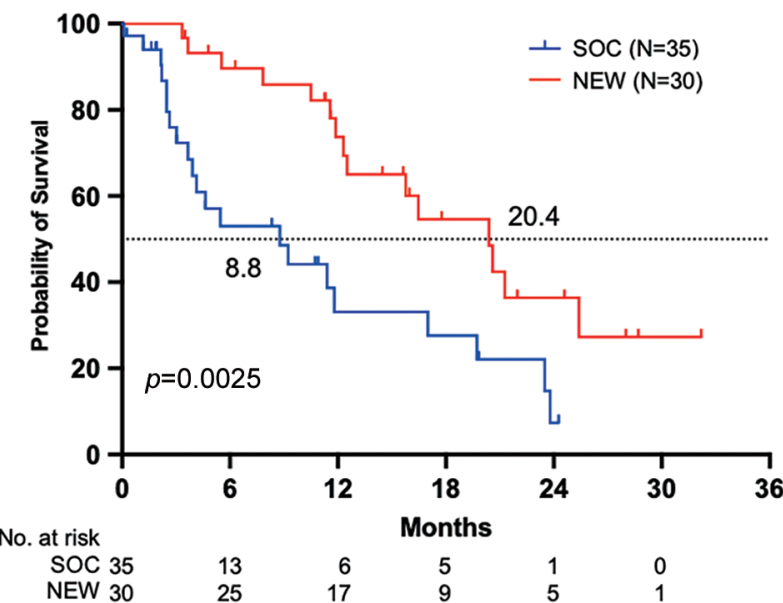

D

TTDOC $\geqq 20.2 \mathrm{M}$

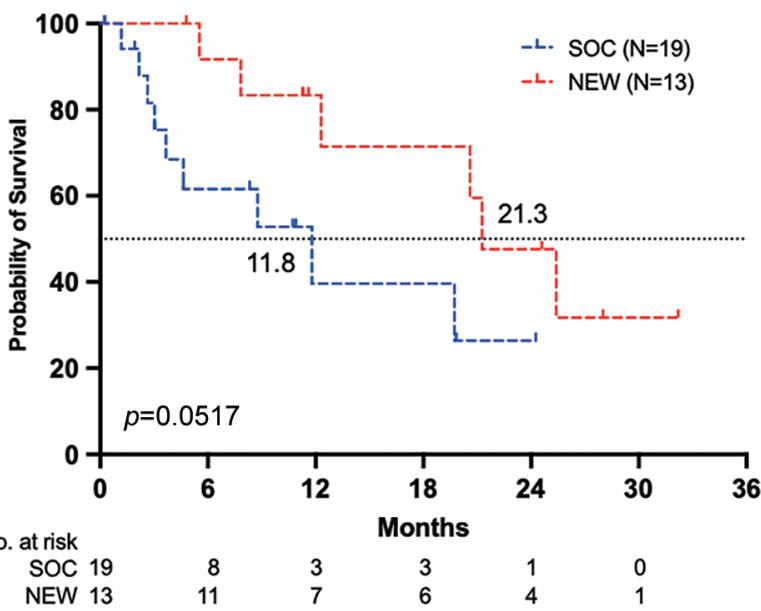

Figure 5. Clinical progression-free survival and overall survival after docetaxel treatment in patients who did not receive cabazitaxel treatment. A. Clinical progression-free survival after docetaxel treatment. B. Overall survival after clinical progression following docetaxel treatment in the standard of care (SOC) group and the NEW group. C. Difference in overall survival from the relapse following docetaxel treatment in the SOC group and the NEW group [to the start of docetaxel treatment $(T T D O C)<20.2$ months]. D. Difference in overall survival from the relapse following docetaxel treatment in the SOC group and the NEW group (TTDOC $\geq 20.2$ months).

when novel ARATs were available after relapse after ADT treatment, OS was significantly longer compared to the era 2011-2014 when they were not available (20).

The current sub-analysis of PROSTAT-BSI revealed that the new therapeutic agents including novel ARATs and/or CBZ improved OS after relapse after DOC treatment in clinical practice. To our knowledge, this is the first report to show that novel ARATs and/or CBZ after relapse after docetaxel treatment improved survival in real-world practice as well as in clinical trials $(5,6,8)$. Furthermore, TTDOC, like TTCRPC, was a prognostic factor from initial $\mathrm{ADT} / \mathrm{CAB}$, but not for relapse after DOC treatment (18). However, the novel therapeutic agents were shown to be effective even after relapse of DOC treatment, regardless of the length of TTDOC in this study. This fact indicates that the AR, which is activated by even low concentrations of adrenal androgens in the CRPC status, is inhibited by the novel ARAT independently of docetaxel. In other words, the hypersensitive AR status is retained with or without docetaxel, and the novel ARAT was shown to be effective because of its low cross-resistance to docetaxel (21).

OS was also improved in the NEW group, excluding patients who received CBZ, compared with the group that 
Table III. Proportional hazard analysis to predict overall survival after docetaxel.

\begin{tabular}{|c|c|c|c|c|}
\hline & Hazard ratio & Lower $95 \%$ & Upper 95\% & $p$-Value \\
\hline Age & 0.994 & 0.954 & 1.035 & 0.756 \\
\hline Age $>69$ & 0.611 & 0.337 & 1.093 & 0.097 \\
\hline $\mathrm{Hb}$ & 0.679 & 0.559 & 0.829 & 0.0002 \\
\hline Gleason score & 1.117 & 0.896 & 1.458 & 0.348 \\
\hline PSA & 1.001 & 0.999 & 1.002 & 0.260 \\
\hline Alp & 1.001 & 1.000 & 1.001 & 0.0002 \\
\hline BAP & 1.006 & 1.002 & 1.009 & 0.002 \\
\hline 1-CTP & 1.047 & 1.016 & 1.072 & 0.005 \\
\hline $1-\mathrm{CTP}>6.00$ & 1.903 & 1.029 & 3.519 & 0.041 \\
\hline CRP & 1.248 & 1.114 & 1.380 & 0.0004 \\
\hline $\mathrm{CRP}>0.23$ & 10.158 & 3.087 & 29.587 & 0.001 \\
\hline BSI & 1.117 & 1.022 & 1.213 & 0.016 \\
\hline Bone met HSN & 1.011 & 1.003 & 1.018 & 0.008 \\
\hline Time to PSA progression & 0.875 & 0.814 & 0.928 & $<0.0001$ \\
\hline Time to BSI progression & 0.898 & 0.842 & 0.947 & $<0.0001$ \\
\hline Time to Clinical progression & 0.860 & 0.791 & 0.924 & $<0.0001$ \\
\hline Time to DOC & 0.996 & 0.985 & 1.006 & 0.501 \\
\hline
\end{tabular}

Hb: Hemoglobin; CRP: C-reactive protein; PSA: prostate specific antigen; Alp: alkaline phosphatase; 1-CTP: cross-linked telopeptide of type 1; BSI: bone scan index; Bone met HSN: Bone metastasis hot spot number; DOC: docetaxel; BAP: bone alkaline phosphatase.

did not receive novel ARATs. However, in this small cohort, no life-prolonging effect of cabazitaxel was observed although the risk for OS tended to be reduced with $\mathrm{CBZ}$. This should be investigated in a larger population to confirm the usefulness of CBZ.

Univariate proportional hazards analysis revealed that hemoglobin, ALP, 1-CTP, BAP, CRP, and BSI and number of hot spots in bone-scintigraphy just before docetaxel treatment were significant predictors of all-cause death. Romero et al. also reported that the predictors of survival with abiraterone for mCRPC were time suffering from prostate cancer prior to treatment with abiraterone, pain intensity, PSA, Alp, and LDH levels (22). These baseline values are expected to be useful in considering how much prognosis can be expected with treatment with docetaxel, new ARATs, and subsequent treatment.

Recently, global phase III trials were conducted to determine whether upfront abiraterone (LATITUDE trial), apalutamide (TITAN trial), or enzalutamide (ARCHES trial) in combination with standard ADT for mHSPC improves OS, and demonstrated the efficacy of upfront novel ARAT for OS (23-26). It is hypothesized that the proportion of patients with mHSPC treated with upfront novel ARAT will increase in the future. However, when using second generation ARAT as upfront treatment, those drugs would be continued until the disease progresses, be more expensive, and have long-term toxicities such as hypertension, cardiovascular disease, bone loss, fractures, and fall $(23,24)$. It is often experienced that it is difficult to give upfront treatment to patients with high complications or poor economic status. Therefore, it is important to prove that the new treatment is useful even after DOC treatment in clinical practice. Moreover, since the risk classifications used in these clinical trials are prognostic factors, and the predictors of the therapeutic effect of upfront novel ARAT are unknown yet, it is necessary to clarify in which patients upfront novel ARAT is beneficial. The results of this subanalysis clearly demonstrated that the novel ARAT is effective even after relapse following DOC treatment if novel ARAT treatment was not performed prior to DOC. Hung et al. reported that docetaxel rechallenge improved survival in patients with mCRPC (27). Whether a novel ARAT should be administered first or DOC first after conversion to CRPC, and what treatment should be performed after relapse following DOC treatment and the subsequent use of a novel ARAT, should be considered according to the various situations of patients.

The present study has some limitations. First, since the present study is a sub-analysis of PROSTAT-BSI, the number of evaluable patients who relapsed after DOC treatment was limited. Second, the study was not randomized regarding the use of therapeutic agents. When patients relapsed after DOC treatment, their physicians might have considered for their therapeutic decision factors such as the condition and the insurance coverage of the patients. Even in the era when novel ARAT was available, there might be a strong bias in the SOC group against novel ARAT, because the rapid progression of $\mathrm{mCRPC}$ after relapse could result in poor 
Table IV. Proportional hazard analysis to predict all-cause death with respect to ARATs and cabazitaxel.

\begin{tabular}{|c|c|c|c|c|c|}
\hline & $\begin{array}{l}\text { Time from docetaxel or } \\
\text { clinical progression }\end{array}$ & Hazard ratio & Lower $95 \%$ & Upper 95\% & $p$-Value \\
\hline \multicolumn{6}{|l|}{ A. Univariable analysis } \\
\hline \multirow[t]{2}{*}{ ARAT } & Docetaxel & 0.415 & 0.230 & 0.757 & 0.005 \\
\hline & Clinical progression & 0.334 & 0.180 & 0.619 & 0.0005 \\
\hline \multirow[t]{2}{*}{ Cabazitaxel } & Docetaxel & 0.643 & 0.314 & 1.314 & 0.209 \\
\hline & Clinical progression & 0.634 & 0.309 & 1.300 & 0.214 \\
\hline \multicolumn{6}{|l|}{ B. ARAT +/- } \\
\hline \multirow[t]{2}{*}{ All patients } & Docetaxel & 0.415 & 0.230 & 0.750 & 0.004 \\
\hline & Clinical progression & 0.334 & 0.180 & 0.619 & 0.001 \\
\hline \multirow[t]{2}{*}{ Patients with cabazitaxel excluded } & Docetaxel & 0.420 & 0.215 & 0.822 & 0.011 \\
\hline & Clinical progression & 0.363 & 0.183 & 0.720 & 0.004 \\
\hline \multicolumn{6}{|l|}{ C. ARAT $+/-$ and PSA $>/ \leq 16.7$} \\
\hline All patients & Docetaxel & & & & \\
\hline PSA $>16.7$ & & 1.815 & 1.002 & 3.288 & 0.049 \\
\hline \multirow[t]{2}{*}{ ARAT } & & 0.387 & 0.212 & 0.704 & 0.002 \\
\hline & Clinical progression & & & & \\
\hline PSA $>16.7$ & & 1.843 & 1.004 & 3.384 & 0.049 \\
\hline ARAT & & 0.291 & 0.153 & 0.552 & 0.0002 \\
\hline \multicolumn{6}{|l|}{ Patients with cabazitaxel excluded } \\
\hline & Docetaxel & & & & \\
\hline PSA $>16.7$ & & 1.833 & 0.935 & 3.594 & 0.078 \\
\hline \multirow[t]{2}{*}{ ARAT } & & 0.433 & 0.221 & 0.848 & 0.015 \\
\hline & Clinical progression & & & & \\
\hline PSA $>16.7$ & & 2.083 & 1.051 & 4.130 & 0.036 \\
\hline ARAT & & 0.333 & 0.166 & 0.669 & 0.002 \\
\hline
\end{tabular}

ARAT: Androgen receptor axis-targeted agent; PSA: prostate specific antigen.

prognosis. Third, the prognosis of prostate cancer patients treated at academic centers might be better than those treated at non-academic centers as reported by Shiota et al. (28). The differences in treatment policies among institutions might affect the therapeutic strategy after relapse following DOC treatment, which in turn may affect prognosis. However, since the PROSTAT-BSI study used biochemical tests and bone scintigraphy with BSI at regular timings, the progress of the SOC and NEW groups seems to be relatively consistently evaluated.

In conclusion, the present study revealed that new therapeutic agents, such as novel ARATs and CBZ for postdocetaxel relapse of $\mathrm{mCRPC}$ improved prognosis by about one year over standard of care or best supportive care, independent of the length of time from the primary ADT to docetaxel treatment in real-world clinical practice if ARATs treatments were not performed prior DOC treatment. We recommend that the appropriate timing for the use of ARAT should be considered, taking into consideration the patient's general condition and financial situation.

\section{Conflicts of Interest}

Author Mizokami has received research grants and Honoraria from FUJIFILM Toyama Chemical Co., Ltd. (Tokyo, Japan).

\section{Authors' Contributions}

Conceived and designed the analysis: AM, KN. Data collection and statistical analysis: AM and NK. Contribution of study patients: AM, KN, HM, TI, ST, HS, KH, YS, MK, and HE. Supervisor: KN. Discussion: AM, NK, HM, and TI. All Authors read and approved the final manuscript.

\section{Acknowledgements}

The Authors appreciate the institutions that cooperated in the inclusion of patients in the PROSTAT-BSI study. This study was partly supported by funds from FUJIFILM Toyama Chemical Co., Ltd. (Tokyo, Japan).

\section{References}

1 Siegel RL, Miller KD, Fuchs HE and Jemal A: Cancer statistics, 2021. CA Cancer J Clin 71(1): 7-33, 2021. PMID: 33433946. DOI: $10.3322 /$ caac. 21654

2 Chi KN, Kheoh T, Ryan CJ, Molina A, Bellmunt J, Vogelzang NJ, Rathkopf DE, Fizazi K, Kantoff PW, Li J, Azad AA, Eigl BJ, Heng DY, Joshua AM, de Bono JS and Scher HI: A prognostic index model for predicting overall survival in patients with metastatic castration-resistant prostate cancer treated with abiraterone acetate after docetaxel. Ann Oncol 27(3): 454-460, 2016. PMID: 26685010. DOI: 10.1093/annonc/mdv594 
3 Halwani AS, Rasmussen KM, Patil V, Li CC, Yong CM, Burningham Z, Gupta S, Narayanan S, Lin SW, Carroll S, Mhatre SK, Graff JN, Dreicer R and Sauer BC: Real-world practice patterns in veterans with metastatic castration-resistant prostate cancer. Urol Oncol 38(1): 1.e1-1.e10, 2020. PMID: 31704142. DOI: 10.1016/j.urolonc.2019.09.027

4 Fizazi K, Scher HI, Molina A, Logothetis CJ, Chi KN, Jones RJ, Staffurth JN, North S, Vogelzang NJ, Saad F, Mainwaring P, Harland S, Goodman OB Jr, Sternberg CN, Li JH, Kheoh T, Haqq CM, de Bono JS and COU-AA-301 Investigators: Abiraterone acetate for treatment of metastatic castrationresistant prostate cancer: final overall survival analysis of the COU-AA-301 randomised, double-blind, placebo-controlled phase 3 study. Lancet Oncol 13(10): 983-992, 2012. PMID: 22995653. DOI: 10.1016/S1470-2045(12)70379-0

5 Ryan CJ, Smith MR, Fizazi K, Saad F, Mulders PF, Sternberg CN, Miller K, Logothetis CJ, Shore ND, Small EJ, Carles J, Flaig TW, Taplin ME, Higano CS, de Souza P, de Bono JS, Griffin TW, De Porre P, Yu MK, Park YC, Li J, Kheoh T, Naini V, Molina A, Rathkopf DE and COU-AA-302 Investigators: Abiraterone acetate plus prednisone versus placebo plus prednisone in chemotherapy-naive men with metastatic castration-resistant prostate cancer (COU-AA-302): final overall survival analysis of a randomised, double-blind, placebocontrolled phase 3 study. Lancet Oncol 16(2): 152-160, 2015. PMID: 25601341. DOI: 10.1016/S1470-2045(14)71205-7

6 Scher HI, Fizazi K, Saad F, Taplin ME, Sternberg CN, Miller K, de Wit R, Mulders P, Chi KN, Shore ND, Armstrong AJ, Flaig TW, Fléchon A, Mainwaring P, Fleming M, Hainsworth JD, Hirmand M, Selby B, Seely L, de Bono JS and AFFIRM Investigators: Increased survival with enzalutamide in prostate cancer after chemotherapy. N Engl J Med 367(13): 1187-1197, 2012. PMID: 22894553. DOI: 10.1056/NEJMoa1207506

7 Armstrong AJ, Lin P, Tombal B, Saad F, Higano CS, Joshua AM, Parli T, Rosbrook B, van Os S and Beer TM: Five-year survival prediction and safety outcomes with enzalutamide in men with chemotherapy-naïve metastatic castration-resistant prostate cancer from the PREVAIL trial. Eur Urol 78(3): 347-357, 2020. PMID: 32527692. DOI: 10.1016/j.eururo.2020.04.061

8 de Bono JS, Oudard S, Ozguroglu M, Hansen S, Machiels JP, Kocak I, Gravis G, Bodrogi I, Mackenzie MJ, Shen L, Roessner M, Gupta S, Sartor AO and TROPIC Investigators: Prednisone plus cabazitaxel or mitoxantrone for metastatic castration-resistant prostate cancer progressing after docetaxel treatment: a randomised open-label trial. Lancet 376(9747): 1147-1154, 2010. PMID: 20888992. DOI: 10.1016/S01406736(10)61389-X

9 Kimura G, Yonese J, Fukagai T, Kamba T, Nishimura K, Nozawa M, Mansbach H, Theeuwes A, Beer TM, Tombal B and Ueda T: Enzalutamide in Japanese patients with chemotherapynaïve, metastatic castration-resistant prostate cancer: A post-hoc analysis of the placebo-controlled PREVAIL trial. Int J Urol 23(5): 395-403, 2016. PMID: 27018069. DOI: 10.1111/iju.13072

10 Beer TM, Armstrong AJ, Rathkopf DE, Loriot Y, Sternberg CN, Higano CS, Iversen P, Bhattacharya S, Carles J, Chowdhury S, Davis ID, de Bono JS, Evans CP, Fizazi K, Joshua AM, Kim CS, Kimura G, Mainwaring P, Mansbach H, Miller K, Noonberg SB, Perabo F, Phung D, Saad F, Scher HI, Taplin ME, Venner PM, Tombal B and PREVAIL Investigators: Enzalutamide in metastatic prostate cancer before chemotherapy. N Engl J Med
371(5): 424-433, 2014. PMID: 24881730. DOI: 10.1056/ NEJMoa1405095

11 Satoh T, Uemura H, Tanabe K, Nishiyama T, Terai A, Yokomizo A, Nakatani T, Imanaka K, Ozono S and Akaza H: A phase 2 study of abiraterone acetate in Japanese men with metastatic castration-resistant prostate cancer who had received docetaxelbased chemotherapy. Jpn J Clin Oncol 44(12): 1206-1215, 2014. PMID: 25425730. DOI: 10.1093/jjco/hyu 148

12 Matsubara N, Uemura H, Satoh T, Suzuki H, Nishiyama T, Uemura H, Hashine K, Imanaka K, Ozono S and Akaza H: A phase 2 trial of abiraterone acetate in Japanese men with metastatic castration-resistant prostate cancer and without prior chemotherapy (JPN-201 study). Jpn J Clin Oncol 44(12): 12161226, 2014. PMID: 25320340. DOI: $10.1093 /$ jjco/hyu 149

13 Nakajima K, Kaneko G, Takahashi S, Matsuyama H, Shiina H, Ichikawa T, Horikoshi H, Hashine K, Sugiyama Y, Miyao T, Kamiyama M, Harada K, Ito A, Mizokami A and PROSTAT-BSI Investigators: Role of bone scan index in the prognosis and effects of therapy on prostate cancer with bone metastasis: Study design and rationale for the multicenter Prostatic Cancer Registry of Standard Hormonal and Chemotherapy Using Bone Scan Index (PROSTAT-BSI) study. Int J Urol 25(5): 492-499, 2018. PMID: 29633398. DOI: 10.1111/iju.13556

14 Nakajima K, Mizokami A, Matsuyama H, Ichikawa T, Kaneko G, Takahashi S, Shiina H, Horikoshi H, Hashine K, Sugiyama Y, Miyao T, Kamiyama M, Harada K, Ito A and PROSTAT-BSI Investigators: Prognosis of patients with prostate cancer and bone metastasis from the Japanese Prostatic Cancer Registry of Standard Hormonal and Chemotherapy Using Bone Scan Index cohort study. Int J Urol 28(9): 955-963, 2021. PMID: 34148264. DOI: $10.1111 /$ iju.14614

15 Schrader AJ, Boegemann M, Ohlmann CH, Schnoeller TJ, Krabbe LM, Hajili T, Jentzmik F, Stoeckle M, Schrader M, Herrmann E and Cronauer MV: Enzalutamide in castrationresistant prostate cancer patients progressing after docetaxel and abiraterone. Eur Urol 65(1): 30-36, 2014. PMID: 23849416. DOI: $10.1016 /$ j.eururo.2013.06.042

16 Miyake H, Matsushita Y, Tamura K, Motoyama D, Ito T, Sugiyama $\mathrm{T}$ and Otsuka A: Impact of prior androgen receptoraxis-targeted agents on the clinical activity of subsequent docetaxel in patients with metastatic castration-resistant prostate cancer: comparative assessment between abiraterone acetate and enzalutamide. Med Oncol 34(12): 200, 2017. PMID: 29164346. DOI: $10.1007 / \mathrm{s} 12032-017-1060-9$

17 Frees S, Akamatsu S, Bidnur S, Khalaf D, Chavez-Munoz C, Struss W, Eigl BJ, Gleave M, Chi KN and So A: The impact of time to metastasis on overall survival in patients with prostate cancer. World J Urol 36(7): 1039-1046, 2018. PMID: 29488095. DOI: $10.1007 / \mathrm{s} 00345-018-2236-4$

18 Miyake H, Matsushita Y, Watanabe H, Tamura K, Motoyama D, Ito T, Sugiyama T and Otsuka A: Prognostic significance of time to castration resistance in patients with metastatic castrationsensitive prostate cancer. Anticancer Res 39(3): 1391-1396, 2019. PMID: 30842173. DOI: 10.21873/anticanres.13253

19 Francini E, Gray KP, Shaw GK, Evan CP, Hamid AA, Perry CE, Kantoff PW, Taplin ME and Sweeney CJ: Impact of new systemic therapies on overall survival of patients with metastatic castration-resistant prostate cancer in a hospital-based registry. Prostate Cancer Prostatic Dis 22(3): 420-427, 2019. PMID: 30643173. DOI: 10.1038/s41391-018-0121-2 
20 Iwamura H, Hatakeyama S, Narita S, Arai Y, Habuchi T and Ohyama C: Prognosis of metastatic castration-resistant prostate cancer in the era of the second-generation androgen receptortargeted agents: A retrospective multicenter study. Int J Urol 28(1): 125-127, 2021. PMID: 33034051. DOI: 10.1111/iju.14392

21 Mizokami A, Kadono Y, Kitagawa Y, Izumi K and Konaka H: Therapies for castration-resistant prostate cancer in a new era: The indication of vintage hormonal therapy, chemotherapy and the new medicines. Int J Urol 24(8): 566-572, 2017. PMID: 28577511. DOI: $10.1111 /$ iju.13372

22 Jimenez Romero ME, Gallego MC, Navarro Serrato JC, Sanchez Hurtado MA and Santotoribio JD: Treatment of metastatic castration-resistant prostate cancer patients with abiraterone acetate and prednisone and corresponding survival prognostic factors. Anticancer Res 41(8): 3955-3968, 2021. PMID: 34281859. DOI: 10.21873 /anticanres. 15192

23 Fizazi K, Tran N, Fein L, Matsubara N, Rodriguez-Antolin A, Alekseev BY, Özgüroğlu M, Ye D, Feyerabend S, Protheroe A, Sulur G, Luna Y, Li S, Mundle S and Chi KN: Abiraterone acetate plus prednisone in patients with newly diagnosed highrisk metastatic castration-sensitive prostate cancer (LATITUDE) final overall survival analysis of a randomised, double-blind, phase 3 trial. Lancet Oncol 20(5): 686-700, 2019. PMID: 30987939. DOI: 10.1016/S1470-2045(19)30082-8

24 Suzuki H, Shin T, Fukasawa S, Hashine K, Kitani S, Ohtake N, Shibayama K, Tran N, Mundle S, Fizazi K and Matsubara N: Efficacy and safety of abiraterone acetate plus prednisone in Japanese patients with newly diagnosed, metastatic hormonenaive prostate cancer: final subgroup analysis of LATITUDE, a randomized, double-blind, placebo-controlled, phase 3 study. Jpn J Clin Oncol 50(7): 810-820, 2020. PMID: 32188988. DOI: $10.1093 /$ jjco/hyaa030
25 Chi KN, Chowdhury S, Bjartell A, Chung BH, Pereira de Santana Gomes AJ, Given R, Juárez A, Merseburger AS, Özgüroğlu M, Uemura H, Ye D, Brookman-May S, Mundle SD, McCarthy SA, Larsen JS, Sun W, Bevans KB, Zhang K, Bandyopadhyay $\mathrm{N}$ and Agarwal N: Apalutamide in patients with metastatic castration-sensitive prostate cancer: Final survival analysis of the randomized, double-blind, phase III TITAN study. J Clin Oncol 39(20): 2294-2303, 2021. PMID: 33914595. DOI: $10.1200 / J C O .20 .03488$

26 Armstrong AJ, Szmulewitz RZ, Petrylak DP, Holzbeierlein J, Villers A, Azad A, Alcaraz A, Alekseev B, Iguchi T, Shore ND, Rosbrook B, Sugg J, Baron B, Chen L and Stenzl A: ARCHES: A randomized, phase III study of androgen deprivation therapy with enzalutamide or placebo in men with metastatic hormonesensitive prostate cancer. J Clin Oncol 37(32): 2974-2986, 2019. PMID: 31329516. DOI: 10.1200/JCO.19.00799

27 Hung SC, Chang LW, Li JR, Wang SS, Yang CK, Chen CS, Lu $\mathrm{K}$, Chen CC, Wang SC, Lin CY, Cheng CL, Ou YC and Chiu $\mathrm{KY}$ : Docetaxel rechallenge improves survival in patients with metastatic castration-resistant prostate cancer: a retrospective study. In Vivo 35(6): 3509-3519, 2021. PMID: 34697189. DOI: 10.21873/invivo.12653

28 Shiota M, Sumikawa R, Onozawa M, Hinotsu S, Kitagawa Y, Sakamoto S, Kawai T, Eto M, Kume H, Akaza H and Japan Study Group of Prostate Cancer (J-CaP): Regional and facility disparities in androgen deprivation therapy for prostate cancer from a multi-institutional Japan-wide database. Int J Urol 28(5): 584-591, 2021. PMID: 33629386. DOI: 10.1111/iju.14518

Received December 23, 2021

Revised January 13, 2022

Accepted December 14, 2022 